\title{
CONTROLE ALTERNATIVO DO MÍLDIO DA VIDEIRA COM EXTRATO AQUOSO DE CINAMOMO E ÓLEO VEGETAL
}

\author{
C.M. da Silva ${ }^{1 *}$, R.V. Botelho², C.M.R.D. Faria ${ }^{2}$, T.P. Stadler ${ }^{2}$ \\ ${ }^{1}$ Universidade Estadual de Maringá, Departamento de Agronomia, Av. Colombo, 5700, CEP 87020-900, \\ Maringá, PR, Brasil. E-mail: crismendes86@hotmail.com
}

\section{RESUMO}

Este trabalho teve como objetivo avaliar o efeito do extrato aquoso de cinamomo (Melia azederach) no controle de Plasmopara viticola. Para o teste de germinação de esporângios do oomiceto foram utilizadas as concentrações de $0,5,10,15,20$ e $25 \mathrm{~mL} \mathrm{~L}^{-1}$ de extrato aquoso de cinamomo (EC), além dos tratamentos com mancozebe e calda bordalesa. No experimento em casa de vegetação e a campo foram estudadas as concentrações de 0, 30, 40 e $50 \mathrm{~mL} \mathrm{~L}^{-1}$ de EC (1:10 p/v), além de um tratamento com calda bordalesa (1:1:100). No segundo experimento, em condições de campo, os tratamentos foram: $0,10,20,30,40$ e $50 \mathrm{~mL} \mathrm{~L}^{-1}$ de EC, acrescidos de óleo vegetal a $2,5 \mathrm{~mL} \mathrm{~L}^{-1}$, calda bordalesa e testemunha absoluta. No teste de germinação, verificou-se maior inibição de $P$. viticola às 2 horas após a incubação, para as concentrações de 20 e $25 \mathrm{~mL} \mathrm{~L}^{-1}$ de EC com uma redução de 66,5 e 62,0\%, respectivamente. Em condições de casa de vegetação o EC a 40 e $50 \mathrm{~mL}$ $\mathrm{L}^{-1}$ apresentou reduções de 70,0\% e 86,0\% da doença, respectivamente. Enquanto que as mesmas concentrações, no primeiro ciclo do experimento a campo, apresentaram um decréscimo de $34,0 \%$ e 31,0\%, respectivamente. No segundo ciclo, o uso de óleo vegetal como adjuvante mascarou o efeito do EC e a aplicação isolada de óleo vegetal reduziu em $76,3 \%$ a área abaixo da curva de progresso da doença (AACPD), similar aos resultados obtidos com todas as concentrações de EC e com a calda bordalesa.

PALAVRAS-CHAVES: Vitisvinifera, lírio-da-índia, agroecologia, Plasmoparaviticola, Melia azederach.

\begin{abstract}
ALTERNATIVE CONTROLOF DOWNY MILDEW WITH AQUEOUSEXTRACTSOF CHINABERRY AND VEGETABLE OIL. The aim of the present study was to evaluate the effect of aqueous extract of chinaberry (Melia azedarach) in the control of Plasmopara viticola. For the germination test of sporangia of the oomycete, concentrations of $0,5,10,15,20$ and $25 \mathrm{~mL} \mathrm{~L}^{-1}$ of aqueous extract of chinaberry (EC) were used, as well as treatments with mancozeb and bordeaux mixture. The experiment in the greenhouse and field involved concentrations of $0,30,40$ and $50 \mathrm{~mL} \mathrm{~L}^{-1}$ of EC $(1: 10 \mathrm{w} / \mathrm{v})$ and a treatment with bordeaux mixture (1:1:100). In the second experiment in the field the treatments were: $0,10,20,30,40$ and $50 \mathrm{~mL} \mathrm{~L}^{-1}$ of EC with an added $2.5 \mathrm{~mL} \mathrm{~L}^{-1}$ of vegetable oil, the bordeaux mixture and an absolute control. In the germination test, there was highest inhibition of $P$. viticola at 2 hours after incubation at $20^{\circ} \mathrm{C}$, for the 20 and $25 \mathrm{~mL} \mathrm{~L}^{-1}$ concentrations of the EC, with a reduction of 66.5 and $62.0 \%$, respectively. In the greenhouse conditions, the EC at a concentration of 40 and $50 \mathrm{~mL} \mathrm{~L}^{-1}$ showed a reduction of $70.0 \%$ and $86.0 \%$ of the disease, respectively, while the same concentrations in the first cycle of the field experiment showed a decrease of $34.0 \%$ and $31.0 \%$, respectively. However, in the second cycle, the use of vegetable oil as an adjunct masked the effect of the EC, and the isolated application of vegetable oil decreased the area under the disease progress curve (ADPC) by $76.3 \%$, similar to results obtained with all concentrations of $\mathrm{EC}$ and with the bordeaux mixture.
\end{abstract}

KEY WORDS: Vitis vinifera, lily-of-india, agroecology, Plasmopara viticola, Melia azederach.

${ }^{2}$ Universidade Estadual do Centro Oeste, Departamento de Agronomia, Guarapuava, PR, Brasil.

*Parte da dissertação de mestrado apresentada à Universidade Estadual do Centro Oeste, para a obtenção do título de mestre. Bolsista Capes. 


\section{INTRODUÇÃO}

Um dos fatores a serem manejados para obtenção da máxima produtividade deum vinhedoéo controle do míldio, doença causada pelo oomiceto Plasmopara viticola [(Berkeley \& M. A. Curtis) Berlese \& De Toni)], sendo responsável por prejuízos significativos no sul do Brasil, assim como em outras regiões vitícolas do mundo (CZERMAinski; SôNego, 2004).

Essa doença afeta todos os órgãos verdes da planta, incidindo sobrefolhas, inflorescências efrutos jovens. Nas folhas o primeiro sintoma é caracterizado pelo aparecimento de manchas de óleo na face superior de coloração verde-clara a amarela e, em condições de alta umidade, ocorre o surgimento na face inferior de um mofo branco, que corresponde à frutificação do patógeno. As inflorescências infectadas secam e caem. Nos cachos, após o pegamento, as bagas jovens ficam amareladas, onde também pode ocorrer esporulação (KuHN et al., 2003).

De forma geral, o produtor realiza pulverizações semanais com intuito de garantir a sua produção e os fungicidas sintéticos utilizados para o controle dessa doença são: cimoxanil, azoxistrobina e mancozebe, entre outros (CHAVARRIA et al., 2007). No entanto, segundo Rosa et al. (2008), o controle do míldio pelo uso exclusivo de fungicidas não tem proporcionado resultados satisfatórios.

A falta de cultivares resistentes, comercialmente aceitáveis, intensifica a necessidade de métodos alternativos de controle de doenças. Portanto, produtos naturais como extratos de plantas que apresentem substâncias antifúngicas podem oferecer alternativas aos fungicidas sintéticos (COHEN et al., 2006). Porém, no Brasil, há um grande número descrito de plantas tóxicas, as quais muitas vezes são utilizadas no controle alternativo, entretanto, em estudos com alevinos de carpa comum, o extrato aquoso de cinamomo não se apresentou tóxico. Além disso, apesar de poder matar suínos, aparentemente bovinos e aves não são suscetíveis (TOMAZELLi Junior, 2009).

Em relação ao uso do extrato de cinamomo no controle de doenças de plantas, de acordo com CARPINELLA et al. (1999), o extrato etanólico de frutos de cinamomo demonstrou atividade fungistática e fungicida sobre Aspergillusflavus e Fusarium moniliforme. Posteriormente, MiLANESI et al. (2006), ao utilizarem o extrato aquoso de cinamomo microfiltrado nas concentrações 3, 5, 7, 10, 15, 20 e 30\% proporcionaram inibição do crescimento micelial de Fusarium solani entre 61 e $80 \%$, sendo que a maior inibição foi verificada após $48 \mathrm{~h}$ de incubação. JABEEN et al. (2008) também conseguiram suprir o crescimento in vitro do fitopatógeno Ascochyta rabiei, agente causal da ferrugem do grão-de-bico, ao utilizar o extrato de folhas de cinamomo.
Dessa forma, o objetivo deste trabalho foi testar a hipótese que o extrato aquoso de cinamomo pode atuar positivamente no controle de $P$. viticola, além de possivelmente tornar-se uma alternativa a ser adotada pelos viticultores, principalmente para a produção agroecológica. Assim, avaliaram-se os efeitos do extrato aquoso de cinamomo sobre a germinação de esporângios de P. viticola, em laboratório, e a severidade da doença em condições de casa de vegetação e campo.

\section{MATERIAL E MÉTODOS}

\section{Preparo do extrato aquoso de cinamomo}

O preparo do extrato aquoso de cinamomo seguiu a metodologia proposta por MARONEZE; Gallegos (2009). Para isto, frutos de cinamomo maduros (de cor amarelada, lisos, mas tornando-se rugosos) e com sementes foram coletados em Guarapuava, PR, secos em estufa de ventilação forçada a $40^{\circ} \mathrm{C}$, por 48 horas e, em seguida, triturados e misturados à água destilada, na proporção 1:10 $(\mathrm{p} / \mathrm{v})$. As suspensões foram mantidas em frascos transparentes por 48 horas e, posteriormente, filtradas através de um tecido fino, obtendo-se o extrato aquoso, utilizado logo após o preparo, para evitar a fermentação e/ou degradação das substâncias inibitórias do cinamomo.

Para o teste de germinação, o extrato foi esterilizado através da filtragem em membrana Millipore ${ }^{\circledR}$ $0,22 \mu$, para eliminar possíveis contaminações bacterianas, verificadas em estudos preliminares.

\section{Teste de germinação}

Para avaliar o efeito do extrato aquoso de cinamomo (EC) sobre a germinação de $P$. viticola, utilizou-se uma alíquota de $40 \mu \mathrm{L}$ de suspensão de esporos $\left(1,27 \times 10^{5}\right.$ esporângios $\left.\mathrm{mL}^{-1}\right)$ e outra de $40 \mu \mathrm{L}$ de cada concentração de EC $(0,5,10,15,20$ e $25 \mathrm{~mL}$ $\mathrm{L}^{-1}$ ), além da calda bordalesa na proporção 1:1:100 (sulfato de cobre:cal virgem:água) e do fungicida mancozebe $(80 \%)$ a 2,5 g p.c. $\mathrm{L}^{-1}$ como tratamentos padrões. Estas soluções foram colocadas em cada um dos recipientes (pocinhos) de uma placa utilizada em teste Elisa (BALBI-PeÑa et al., 2006).

As placas foram incubadas a $20^{\circ} \mathrm{C}$ no escuro e a paralisação da germinação foi realizada com a adição de $20 \mu \mathrm{L}$ do corante azul algodão com lactofenol às 2, 4, 6, 12 e 24 horas após o início da incubação. As avaliações foram realizadas por meio da observação ao microscópioóptico. Contaram-se cem esporângios por repetição, considerando esporângios germinados aqueles que apresentavam liberação dos zoósporos (NAves et al., 2010) (Fig. 1). 


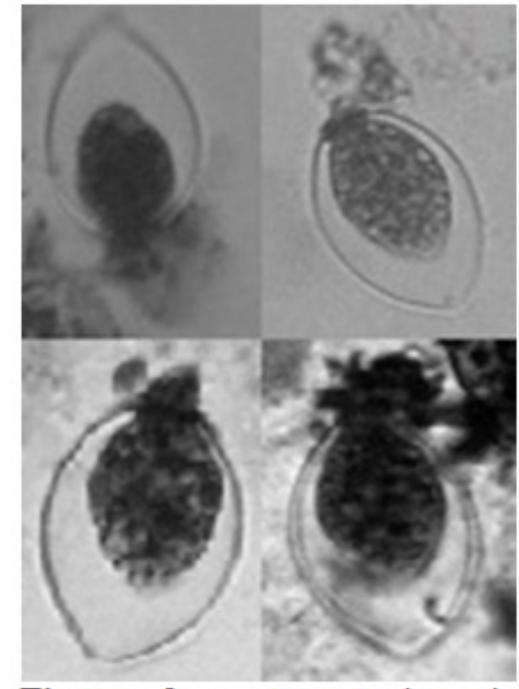

Fig. 1 - Esporângios de Plasmopara viticola.

$\mathrm{O}$ delineamento experimental utilizado foi inteiramente casualizado em esquema fatorial [ $(6 \times 5)$ + 2] com quatro repetições e parcela experimental constituída por cem esporângios. O fator principal constituiu-se das doses de extrato de cinamomo e o fator secundário dos tempos de paralisação da germinação dos esporângios e mais dois tratamentos adicionais padrões (calda bordalesa e mancozebe).

\section{Experimento em casa de vegetação}

O material propagativo da videira cv. Cabernet Sauvignon utilizado para o experimento foi retirado de um pomar experimental no Município de Guarapuava, PR, por ocasião da poda de inverno.

As miniestacas lenhosas foram preparadas com uma gema cada e enterradas em espumas fenólicas em bandejas plásticas preenchidas com água. Em seguida, as bandejas foram mantidas em sala de crescimento vegetativo durante 60 dias, a $25^{\circ} \mathrm{C}$ e fotoperíodo de 12 horas de luz proveniente de lâmpadas fluorescentes (2500 lux). Posteriormente, as miniestacas enraizadas foram transferidas para vasos de plástico medindo $45 \times 17 \times 17 \mathrm{~cm}$, contendo como substrato o produto comercial Plantmax ${ }^{\circledR}$ (Eucatex) e areia, na proporção 1:1, e mantidas em casa de vegetação com nebulização intermitente.

As plantas foram pulverizadas a cada sete dias, com pulverizador manual até o ponto de "escorrimento", com as seguintes concentrações de EC: 0, 30, 40 e $50 \mathrm{~mL} \mathrm{~L}^{-1}$, além do tratamento padrão com calda bordalesa, não se utilizando um produto químico por se tratar de um experimento orgânico.

Após a quinta pulverização, em que as plantas estavam com quatro a seis folhas, elas foram inoculadas com a suspensão de esporângios do fungo $P$. viticola. Para obtenção do inóculo, folhas de videira contaminadas com míldio foram imersas em água destilada autoclavada com Tween 80 para liberação de seus esporângios e, em seguida, realizou-se a calibração do número de esporângios com o auxílio da câmara de Newbauer para padronizar a quantidade de inóculo em 9,2 × $10^{5}$ esporângios $\mathrm{mL}^{-1}$.

As plantas foram inoculadas com a suspensão de esporângios com pulverizador manual até o ponto de "escorrimento" e, em seguida, cobertas com plástico transparente, para criar um microclima úmido e favorável à infecção. As condições de incubação foram de temperatura de 20 a $24{ }^{\circ} \mathrm{C}$ e umidade relativa em torno de $95 \%$. Pela manhã as plantas foram descobertas.

Com o aparecimento dos primeiros sintomas, a severidade do míldio foi avaliada em quatro folhas por planta, previamenteidentificadas, utilizando-se a escala diagramática descrita por AzEvEDo (1997), que possui notas que correspondem de $0 \%$ a $100 \%$ da área foliar lesionada. Com os dados da severidade foi determinada a área abaixo da curva de progresso da doença (AACPD), segundo SHANER; FINNEy (1977). No total, foram realizadas oito avaliações com intervalos de dois dias.

$\mathrm{O}$ delineamento experimental utilizado foi em blocos casualizados com cinco tratamentos, seis repetições e parcela experimental constituída por duas miniestacas (um vaso).

\section{Experimento em campo}

Os experimentos foram conduzidos nos períodos de setembro de 2009 a janeiro de 2010 e de setembro a dezembro de 2010 em vinhedo comercial do cultivar Isabel, localizado no Município de Guarapuava, PR. As coordenadas geográficas locais são: 25²3’36"S 51 $27^{\prime} 19^{\prime \prime} \mathrm{O}$; e $1.120 \mathrm{~m}$ de altitude (INSTiтUTO..., 2000). As plantas com três anos de idade eram enxertadas sobre porta enxerto Paulsen 1103, conduzidas em sistema de espaldeira, com espaçamento 2,5 x 2,0 m.

No primeiro experimento, no ciclo de 2009/2010, os tratamentos foram os mesmos do experimento em casa de vegetação $\left(0,30,40\right.$ e $50 \mathrm{~mL} \mathrm{~L}^{-1}$ de EC), e a calda bordalesa como padrão. No segundo experimento, ciclo de 2010/2011, os tratamentos foram: 0, $10,20,30,40$ e $50 \mathrm{~mL} \mathrm{~L}^{-1}$ de EC, todos adicionadas de óleo vegetal a 2,5 mL L-1 como adjuvante (Natur' L Óleo®, Empresa Stoller do Brasil LTDA), para melhorar a aderência do extrato nas folhas e reduzir a degradação dos compostos do extrato, em função da exposição à radiação solar e às altas temperaturas (BOGORNI, 2003), além dos tratamentos padrões com calda bordalesa e a testemunha absoluta sem tratamento. As pulverizações foram realizadas com intervalo de sete dias, com pulverizador manual (P-1500 Brudden $\AA$, bico cone regulável), volume aplicado de um litro de solução por tratamento, até o ponto de "escorrimento", a partir do início da brotação, totalizando 15 aplicações, para os dois ciclos. 
Com o início dos primeiros sintomas, a severidade do míldio foi avaliada em três folhas do ápice de quatro ramos por planta, utilizando-se a escala diagramática descrita por AzEVEDo (1997). Os ramos foram previamente identificados e escolhidos de forma aleatória. Com os dados da severidade (que possui notas de 0 a $100 \%$ da área foliar lesionada), foi determinada a área abaixo da curva de progresso da doença (AACPD), segundo SHANER; FinNEY (1977). No total foram realizadas oito avaliações com intervalos de sete dias, tanto no primeiro quanto no segundo experimento. $\mathrm{O}$ delineamento experimental foi em blocos ao acaso contendo cinco tratamentos e cinco repetições no primeiro ciclo e oito tratamentos e cinco repetições no segundo ciclo, com parcela experimental constituída por uma planta.

Nos dois experimentos, os resultados foram submetidos à análise de variância e, quando significativo, realizou-se a comparação de médias pelo teste de Tukey e análise de regressão polinomial ao nível de $5 \%$ probabilidade, através do programa estatístico SISVAR (FERREIRA, 2008).
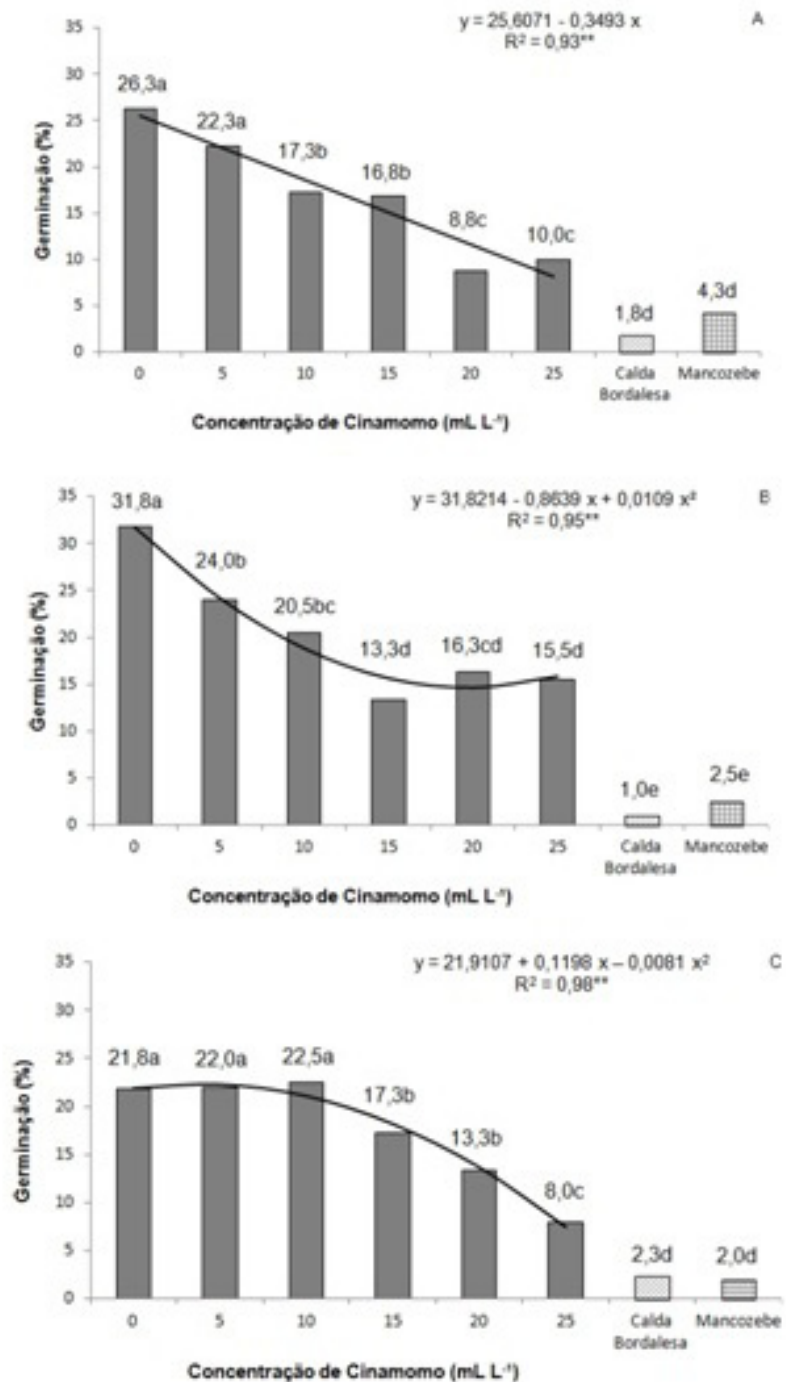

\section{RESULTADOS E DISCUSSÃO}

\section{Teste de germinação}

Para o teste de germinação, foi verificado efeito quadrático em função das concentrações de EC às 4, 6 e 12 horas após o início da incubação dos esporângios, e efeito linear negativo às 2 e 24 horas (Fig. 2). Entre as concentrações de EC, os menores valores foram verificados para as concentrações de 20 e 25 $\mathrm{mL} \mathrm{L}^{-1}$ às 2 horas após incubação, com uma redução deaproximadamente $66,5 \%$ e $62,0 \%$, respectivamente, em relação à testemunha (Fig. 2A). Entretanto, às 4 horas após incubação observou-se para estas mesmas concentrações reduções de apenas 48,7\% e 51,3\%, respectivamente (Fig. 2B). Esse fato pode ter ocorrido devido a perdas das propriedades antifúngicas do extrato de cinamomo, após um período maior de incubação. $\mathrm{O}$ extrato aquoso de cinamomo a $15 \mathrm{~mL}$ $\mathrm{L}^{-1}$ não diferiu estatisticamente das concentrações a 20 e $25 \mathrm{~mL} \mathrm{~L}^{-1}$, apresentando uma redução de $58,2 \%$ da germinação de esporângios às 4 horas após incubação.

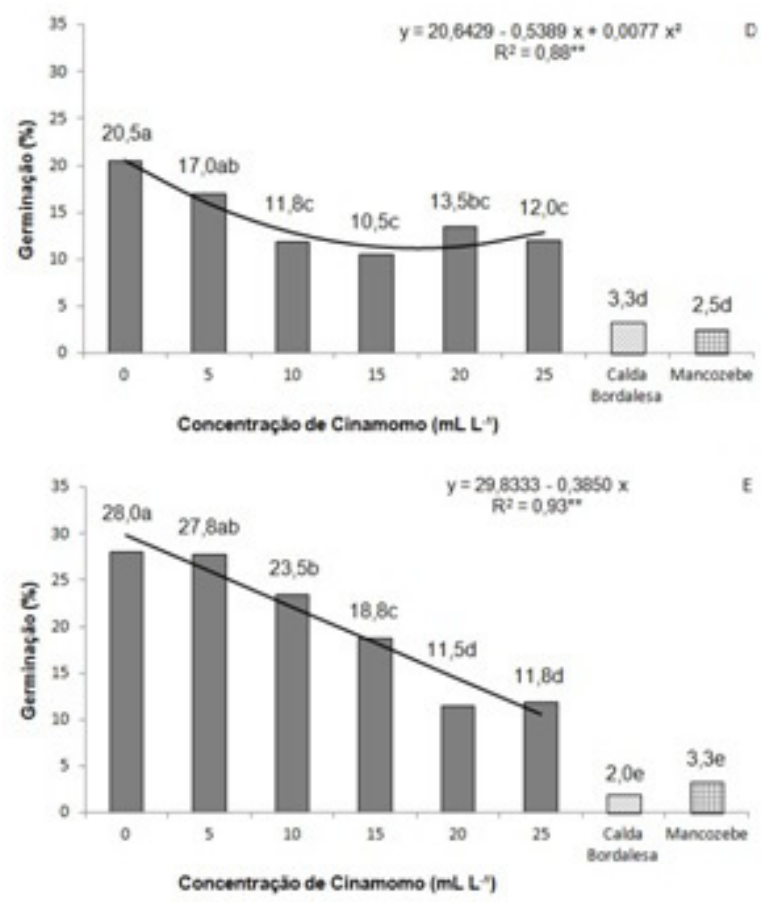

Fig. 2 - Efeito das concentrações de extrato aquoso de cinamomo sobre a germinação de esporângios de Plasmopara viticola às 2 horas (A), 4 horas (B), 6 horas (C), 12 horas (D) e 24 horas (E) após incubação a $20^{\circ} \mathrm{C}$. ${ }^{1}$ Médias seguidas de letras distintas diferem pelo Teste de Tukey ao nível de $5 \%$ de probabilidade. 
Quando o extrato aquoso de cinamomo foi comparado aos tratamentos com calda bordalesa e mancozebe, os tratamentos padrões foram ligeiramente superiores. Entretanto, deve-se considerar que o extrato aquoso de cinamomo apresenta outras vantagens importantes por ser um produto natural, de fácil obtenção e de baixo custo.

Resultados semelhantes foram obtidos por ABOUJAWDAH et al. (2002), que verificaram que o extrato de cinamomo obtido com solvente de éter de petróleo proporcionou inibição da germinação de esporos de Verticillium dahliae (patógeno isolado de murcha vascular em algodoeiro) em 100,0\%; e de Fusarium oxysporium f. sp. melonis (isolado obtido da cultura do melão) em 95,0\%; de Cladosporium spp. em 87,0\%; de Botrytis cinerea em $84 \%$; de Alternaria solani em $75,0 \%$ e de Penicillium sp. em 53,0\%, patógenos isolados de podridões em flores, frutos e sementes. A ação do extrato metanólico de cinamomo foi menor do que a do extrato de éter de petróleo, mesmo assim obteve resultados satisfatórios, com uma redução da germinação de esporos de F. oxysporium f. sp. melonis em $80,0 \%$; de B. cinerea em $54,0 \%$; de Penicillium spp. em $40,0 \%$; de A. solani em $17,0 \%$ e de Cladosporium sp. em $14,0 \%$.

Para a variável AACPD houve efeito linear negativo em função das concentrações do extrato aquoso de cinamomo, sendo que a concentração de $50 \mathrm{~mL}$ $\mathrm{L}^{-1}$ proporcionou melhor controle promovendo uma redução de $86,0 \%$. Este tratamento não se diferiu da concentração de $40 \mathrm{~mL} \mathrm{~L}^{-1}$ e do tratamento padrão com calda bordalesa, onde não houve ocorrência da doença (Fig. 3).

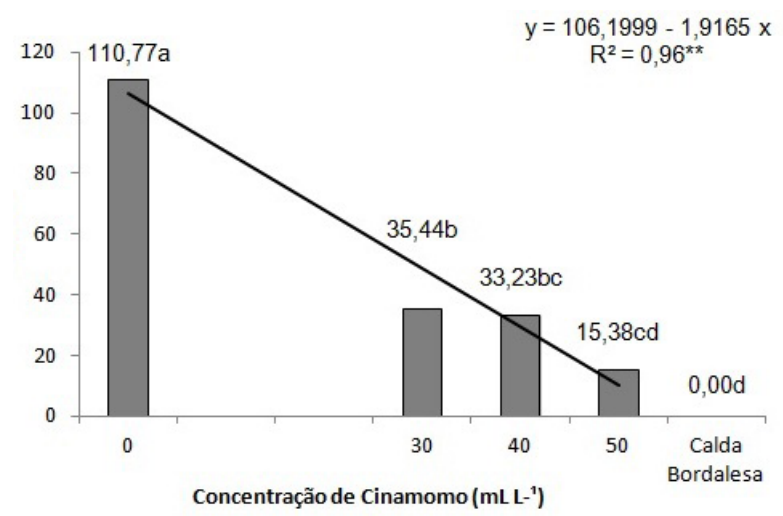

Fig. 3 - Efeito das concentrações de extrato aquoso de cinamomo, na área abaixo da curva de progresso da doença (AACPD), sobre o míldio no cultivar Cabernet Sauvignon em condições de casa de vegetação. ${ }^{1}$ Médias seguidas de letras distintas diferem pelo Teste de Tukey ao nível de $1 \%$ de probabilidade.

Nãohá outros trabalhos com extrato decinamomo em plantas inoculadas, mas resultados importantes foram obtidos com extrato de nim, planta pertencente à mesma famíla Meliaceae e que contém os mesmos princípios ativos do cinamomo (SEFFrin et al., 2008).
CARNEIRO et al. (2007), por exemplo, verificaram controle do oídio do feijoeiro, em condições de casa de vegetação. Ó́leo de nim nas concentrações de $0,5 \%$; 1,0\% e 1,5\%, aplicado após a inoculação do patógeno, apresentou-se tão eficiente quanto o fungicida triforine na dose de $4 \mathrm{ml} \mathrm{L}^{-1}$, tendo reduzido em média, 97,0\% do número de manchas/folha.

Do mesmo modo, o óleo emulsionável de nim foi eficiente no controle do oídio do tomateiro quando comparado à testemunha pulverizada apenas com água. Todas as concentrações testadas mantiveram a porcentagem de área foliar afetada igual ou abaixo de $1,0 \%$ com duas pulverizações em sete dias. A testemunha apresentou, ao final do ensaio, mais de 23,0\% de área foliar doente (CARNEIRO, 2003).

\section{Experimento em campo}

Para os resultados de AACPD em condição de campo, no primeiro experimento, observou-se efeito linear negativo em função das concentrações do extrato aquoso de cinamomo. As concentrações de 30, 40 e $50 \mathrm{~mL} \mathrm{~L}^{-1}$ de EC apresentaram um decréscimo de aproximadamente $26,0 \% ; 34,0 \%$ e $31,0 \%$, respectivamente, sendo que todas as concentrações não diferiram estatisticamente dos tratamentos com a calda bordalesa e com a testemunha (Fig. 4A).

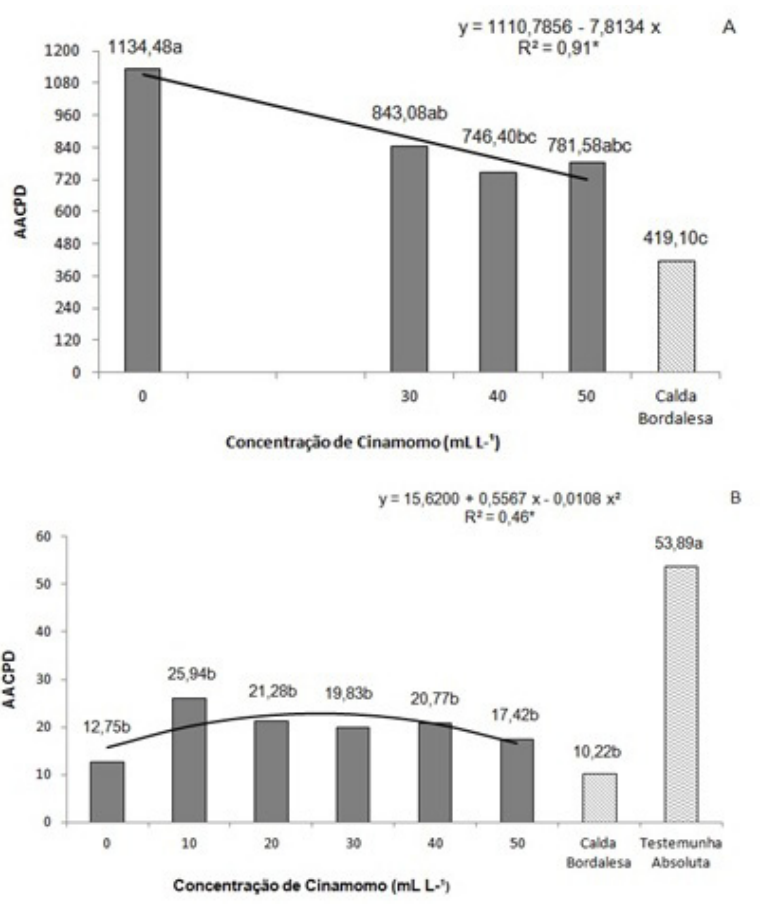

Fig. 4 - Efeito das concentrações de extrato aquoso de cinamomo, na área abaixo da curva de progresso da doença (AACPD) no primeiro (A) e segundo ciclos (B), sobre o míldio no cultivar Isabel em condições de campo. ${ }^{1}$ Médias seguidas de letras distintas diferem pelo Teste de Tukey ao nível de $5 \%$ de probabilidade. 
Os resultados de campo obtidos foram inferiores aos de casa de vegetação, mas isso se deve principalmente às condições extremamente favoráveis ao desenvolvimento da doença no ciclo de 2009/2010, tornando-se um ano atípico para o controle dessa doença, com grande pressão de inóculo do agente etiológico. Durante o período de avaliação (56 dias), observou-se temperatura mínima média mensal de $14^{\circ} \mathrm{C}$ e temperatura máxima média mensal de $24^{\circ}$ C, e uma precipitação média mensal de $254 \mathrm{~mm}$ com longos períodos chuvosos, fatores propícios a ocorrência de severas epidemias (Fig. 5A). Entretanto, no segundo experimento não foram observadas condições tão favoráveis ao desenvolvimento do patógeno, havendo menor precipitação, com média mensal do período de $116 \mathrm{~mm}$ (Fig. 5B).
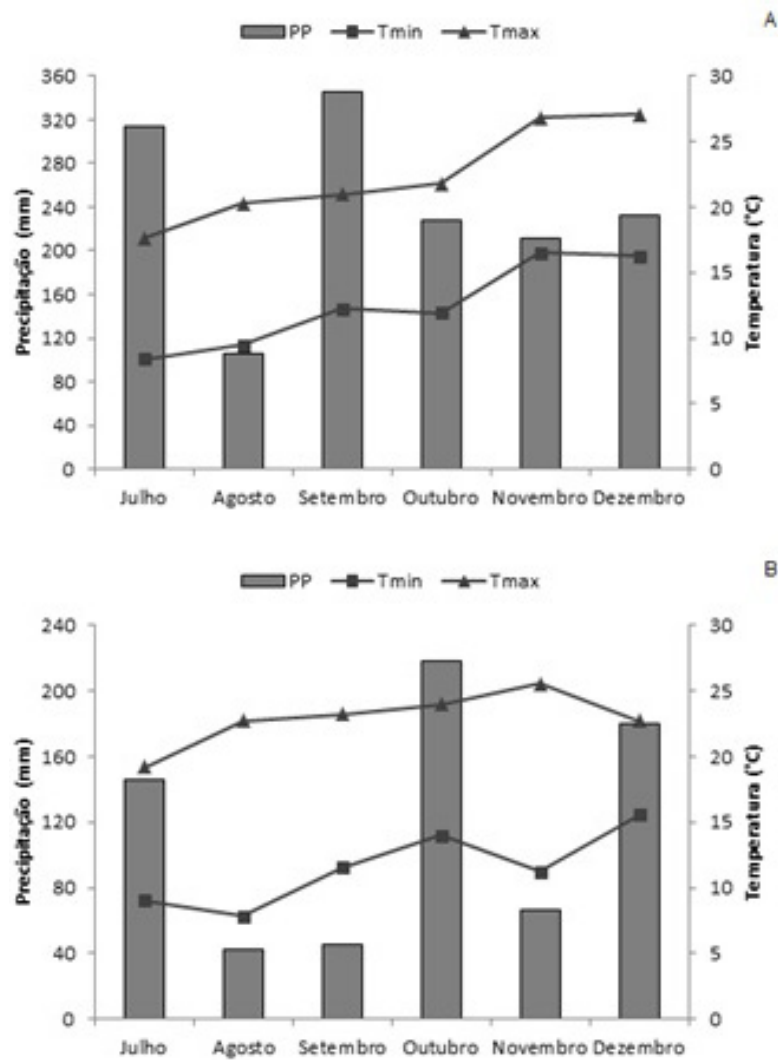

Fig. 5 - Precipitações mensais (mm) e temperaturas mínimas e máximas médias mensais $\left({ }^{\circ} \mathrm{C}\right)$, no primeiro $(\mathrm{A})$ e segundo ciclo (B), no Município de Guarapuava, Paraná (Estação Meteorológica da Unicentro, 2011).

De acordo com GallotTi et al. (2004), temperaturas entre $20-25^{\circ} \mathrm{C}$ e umidade relativa do ar de $95 \%$, bem como chuvas abundantes, são consideradas condições favoráveis ao desenvolvimento do míldio. Ressalta-se que o principal mecanismo de sobrevivência de $P$. viticola é por meio de oósporos presentes no interior de tecidos de folhas senescidas sobre o solo e micélios dormentes em gemas, e para que ocorra a germinação destes oósporos é necessário, principalmente no mês de agosto, temperatura acima de $10^{\circ} \mathrm{C}$ coincidindo com dias de precipitação superior a $10 \mathrm{~mm}$, fato esse ocorrido no transcorrer do experimento conduzido em Guarapuava, PR, predispondo a germinação de oósporos, além de que nesse mês já havia brotos e folhas novas para as infecções primárias (TRAN MANH Sung et al., 1990; CZERMAINSKI; SÔNEGO, 2004).

Não há relatos sobre o efeito de extratos de cinamomo no controle de doenças em condições de campo, HASSANEIN etal. (2008) verificaram a eficiência de extrato de nim sobre os fungos Alternaria solani e Fusarium oxysporium. Os resultados mostraram que, após duas semanas da inoculação de $A$. solani, as plantas de tomateiro pulverizadas com $20 \%$ do extrato aquoso de nim apresentaram uma redução de $42,5 \%$ da incidência do patógeno. E quanto à incidência de F. oxysporium, sementes tratadas com o patógeno e irrigadas com o extrato aquoso de nim obtiveram controle de $81,0 \%$.

No segundo experimento de campo, a aplicação isolada deóleo vegetal diminuiu em $76,3 \%$ a AACPD em relação à testemunha absoluta (sem tratamento), não diferindo dos resultados obtidos com todas as concentrações de extrato aquoso de cinamomo e com o tratamento padrão com calda bordalesa (Fig. 4B). A ação de óleos vegetais no controle de doenças de plantas já havia sido verificado por JUNQUEIRA et al. (2004), em que o óleo de soja apresentou eficiência no controle pós-colheita da antracnose em frutos de manga.

\section{CONCLUSÃO}

Os resultados deste trabalho mostraram que o extrato aquoso de cinamomo foi eficiente no controle da germinação deesporângios de P.viticola. Em condições de casa de vegetação, o extrato apresentou controle da severidade do míldio, porém, em condições de campo os efeitos não foram expressivos, devido principalmenteaosfatores climáticos extremamentefavoráveis ao desenvolvimento da doença. Enquanto que o óleo vegetal, utilizado como adjuvante, controlou o míldio no segundo experimento a campo.

\section{AGRADECIMENTOS}

À Coordenação de Aperfeiçoamento de Pessoal de Nível Superior (CAPES) pela concessão da bolsa à primeira autora. Ao produtor Lauri por ceder a área para instalação do experimento.

\section{REFERÊNCIAS}

ABOU-JAWDAH, Y.; SOBH, H.; SALAMEH, A. Antimycotic activities of selected plant flora, growing 
wild in Lebanon, against phytopathogenic fungi. Journal of Agricultural and Food Chemistry, v.50, n.11, p.32083213, 2002.

AZEVEDO, L.A.S. Manual de quantificação de doenças de plantas. São Paulo: Novartis Biociências- Setor Agro, 1997. 114p.

BALBI-PEÑA, M.I.; BECKER, A.; STANGARLIN, J.R., FRAZENER, G; LOPES, M.C.; SCHWAN-ESTRADA, K.R.F. Controle de Alternaria solani em tomateiro por extratos de Curcuma longa e curcumina - I. Avaliação in vitro. Fitopatologia Brasileira, v.31, n.3, p.310-314, 2006.

BOGORNI, P.C. Efeito de extratos aquosos de Trichilia spp. sobre o desenvolvimento de Spodoptera frugiperda (J. E. Smith) em milho. 2003. 65f. Tese (Doutorado em Agronomia - Área de Entomologia) - Escola Superior de Agricultura Luiz de Queiroz, Universidade de São Paulo, Piracicaba, 2003.

CARNEIRO, S.M.T.P.G. Efeito de extratos de folhas e do óleo de nim sobre o oídio do tomateiro. Summa Phytopathologica, v.29, n.3, p.262-265, 2003.

CARNEIRO, S.M.T.P.G.; PIGNONI, E.; VASCONCELLOS, M.E.C.; GOMES, J.C. Eficácia de extratos de nim para o controle do oídio do feijoeiro. Summa Phytopathologica, v.33, n.1, p.34-39, 2007.

CARPINELLA, M.C.; HERRERO, G.W.; ALONSO, R.A.; PALACIOS, S.M. Antifungal activity of Melia azedarach fruit extracts. Fitoterapia, v.70, n.3, p.296-298, 1999.

CHAVARRIA, G.; SANTOS, H.P.; SÔNEGO, O.R.; MARODIN, G.A.B.; BERGAMASCHI, H.; CARDOSO, L.S. Incidência de doenças e necessidade de controle em cultivo protegido de videira. Revista Brasileira de Fruticultura, v.29, n.3, p.477-482, 2007.

COHEN, Y.; WANG, W.; BEN-DANIEL, B.; BEN-DANIEL, $\mathrm{Y}$. Extracts of Inula viscosa control downy mildew of grapes caused by Plasmopara viticola. Phytopathology, v.96, n.10, p.417-424, 2006.

CZERMAINSKI, A.B.C.; SÔNEGO, O.R. Influência das condições climáticas sobre a eficácia de fungicidas empregados para o controle do míldio em Vitis vinifera. Ciência Rural, v.34, n.1, p. 5-11, 2004.

FERREIRA, D.F. Manual do sistema Sisvar para análises estatísticas. Lavras: UFLA, 2008. 66p.

GALLOTTI, G.J.M.; AANDRADE, E.R.; SÔNEGO, O.R.; GARRIDO, L.R.; GRIGOLETTI JUNIOR, A. Doenças da videira e seu controle em Santa Catarina. Florianópolis: EPAGRI, 2004. 90p. (Boletim técnico 51).

HASSANEIN, N.M.; ABOU ZEID, M.A.; YOUSSEF, K.A.; MAHMOUD, D.A. Efficacy of Leaf Extracts of Neem (Azadirachta indica) and Chinaberry (Melia azedrach) Against Early Blight and Wilt Diseases of Tomato. Australian Journal of Basic and Applied Sciences, v.2, n.2, p.763-772, 2008.

INSTITUTO AGRONÔMICO DO PARANÁ. Cartas climáticas do Paraná. Versão 1.0. Londrina: IAPAR, 2000. 1 CD-ROM.

JABEEN, K.; JAVAID, A.; ATHAR, M. Fungistatic activity of aqueous and organic solvent extracts of Melia azedarach against Ascochyta rabiei. Pakistan Journal of Phytopathology, v.20, n.1, p.143-149, 2008.

JUNQUEIRA, N.T.V.; CHAVES, R.C.; NASCIMENTO, A.C.; RAMOS, V.H.V.; PEIXOTO, J.R.; JUNQUEIRA, L.P. Efeito do óleo de soja no controle da antracnose e na conservação da manga cv. Palmer em pós-colheita. Revista Brasileira de Fruticultura, v.26, n.2, p.222-225, 2004.

KUHN, G. B.; MELO, G. W.; NACHTIGAL, J. C.; MAIA, J. D. G.; NAVES, R. L.; GARRIDO, L. R.; SONEGO, O. R.; KUHN, G. B. Cultivo da videira Niagara Rosada em regiões tropicais do Brasil. Bento Gonçalves: Embrapa Uva e Vinho, 2003. (Sistema de Produção, 5). Disponível em: <http:// sistemasdeproducao.cnptia.embrapa.br/ FontesHTML/Uva/UvaNiagaraRosadaRegioesTropicais/ autores.htm>. Acesso em: 16 out. 2012.

MARONEZE, D.M.; GALLEGOS, D.M.N. Efeito de extrato aquoso de Melia azedarach no desenvolvimento das fases imatura e reprodutiva de Spodoptera frugiperda (J. E. Smith, 1797) (Lepdoptera: Noctuidae). Semina: Ciências Agrárias, v.30, n.3, p.537-550, 2009.

MILANESI, P.; MANZONI, C.G.; WEBER, M.N.D.; BLUME, E.; MUNIZ, M.F.B. Efeito do extrato aquoso de Melia azedarach sobre o crescimento micelial de Fusarium solani. In: CONGRESSO BRASILEIRO DE FITOPATOLOGIA, 39., 2006, Salvador, BA. Resumos. Salvador: 2006. p.137.

NAVES, R.L.; SANTANA, A.P.S.; PAPA, M.F.S.; TEIXEIRA, E.C.Z.; BOLIANI, A.C. Inibição da germinação in vitro de esporangiósporos de Plasmopara viticola por extrato de folhas de melão-de-são caetano. Tropical Plant Pathology, v.35, n.1, p.11, 2010.

ROSA, R.C.T.; CAVALCANTI, V.A. L.B.; COELHO, R.S.B.; PAIVA, J.E. Efeito de produtos alternativos e de fungicidas no controle do míldio da videira. Summa Phytopathologica, v.34, n.3, p.256-258, 2008.

SEFFRIN, R.C.A.S.; COSTA, E.C.; DOMINGUES, L.S.; DEQUECH, S.T.B.; SAUSEN, C.D. Atividade inseticida de meliáceas sobre Diabrotica speciosa (Col., Chrysomelidae). Ciência Rural, v.38, n.7, p.1805-1809, 2008.

SHANER, G.; FINNEY, R.E. The effect of nitrogen fertilization on the expression of slow-mildewing resistance in Knox wheat. Phytopathology, v.67, n.8, p.10511056, 1977. 
TRAN MANH SUNG, C.; STRIZYK, S.; CLERJEAU, M. Simulation of the date of maturity of Plasmopara viticola oospores to predict the severity of primary infection in grapevine. Plant Disease, v.74, n.2, p.120-124, 1990.

TOMAZELLI JÚNIOR, O. Uso de extratos vegetais no controle de larvas de insetos aquáticos (insecta : odontata) predadores de alevinos em viveiros de piscicultura. 2009. $77 \mathrm{f}$.
Dissertação (Mestrado em Ciências - Área de Ciências Ambientais) - Universidade Comunitária Regional de Chapecó, Chapecó, 2009.

Recebido em 6/6/11

Aceito em 21/10/12 